\title{
An assessment of rehabilitation success in an African grassland using ants as bioindicators
}

\begin{tabular}{|c|c|}
\hline $\begin{array}{l}\text { Authors: } \\
\text { Samantha-Le } \\
\text { Mark Roberts } \\
\text { lan Engelbrec } \\
\text { Peter Hawkes }\end{array}$ & $\begin{array}{l}\text { gh Jamison }{ }^{1} \\
\mathrm{on}^{2} \\
\mathrm{ht}^{3} \\
3,4\end{array}$ \\
\hline $\begin{array}{l}\text { Affiliations: } \\
\text { 'Department } \\
\text { Science, Univ } \\
\text { Pretoria, Sou }\end{array}$ & $\begin{array}{l}\text { of Plant } \\
\text { ersity of } \\
\text { h Africa }\end{array}$ \\
\hline $\begin{array}{l}{ }^{2} \text { Centre for In } \\
\text { Department } \\
\text { Entomology, } \\
\text { Pretoria, Sou }\end{array}$ & $\begin{array}{l}\text { Iasion Biology, } \\
\text { r Zoology \& } \\
\text { Jniversity of } \\
\text { h Africa }\end{array}$ \\
\hline $\begin{array}{l}{ }^{3} \text { Department } \\
\text { Entomology, } \\
\text { Pretoria, Sout }\end{array}$ & $\begin{array}{l}\text { of Zoology and } \\
\text { Iniversity of } \\
\text { h Africa }\end{array}$ \\
\hline $\begin{array}{l}{ }^{4} \text { AfriBugs CC, } \\
\text { South Africa }\end{array}$ & Pretoria, \\
\hline $\begin{array}{l}\text { Correspondin } \\
\text { Samantha-Lei } \\
\text { samjam@live }\end{array}$ & $\begin{array}{l}\text { g author: } \\
\text { gh Jamison, } \\
\text { co.za }\end{array}$ \\
\hline $\begin{array}{l}\text { Dates: } \\
\text { Received: } 02 \\
\text { Accepted: } 23 \\
\text { Published: } 29\end{array}$ & $\begin{array}{l}\text { Eeb. } 2016 \\
\text { June } 2016 \\
\text { Sept. } 2016\end{array}$ \\
\hline $\begin{array}{l}\text { How to cite th } \\
\text { Jamison, S-L., } \\
\text { Engelbrecht, I } \\
2016 \text {, 'An asse } \\
\text { rehabilitation } \\
\text { African grassl } \\
\text { as bioindicato } \\
58(1) \text {, a1383. } \\
\text { org/10.4102/ } \\
\text { v58i1.1383 }\end{array}$ & $\begin{array}{l}\text { is article: } \\
\text { Robertson, M., } \\
\text { \& Hawkes, P., } \\
\text { ssment of } \\
\text { success in an } \\
\text { ind using ants } \\
\text { rs', Koedoe } \\
\text { http://dx.doi. } \\
\text { oedoe. }\end{array}$ \\
\hline $\begin{array}{l}\text { Copyright: } \\
\text { @ 2016. The } \\
\text { Licensee: AOS } \\
\text { is licensed un } \\
\text { Creative Comr } \\
\text { Attribution Lic }\end{array}$ & $\begin{array}{l}\text { uthors. } \\
\text { IS. This work } \\
\text { der the } \\
\text { nons } \\
\text { ense. }\end{array}$ \\
\hline Read online: & \\
\hline 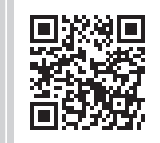 & $\begin{array}{l}\text { Scan this QR } \\
\text { code with your } \\
\text { smart phone or } \\
\text { mobile device } \\
\text { to read online. }\end{array}$ \\
\hline
\end{tabular}

Many studies that evaluate rehabilitation make use of invertebrate bioindicators. Invertebrates, especially ants, make useful indicators as they are sensitive to environmental change. We compared ant assemblages in rehabilitated and control sites in the Rietvlei Nature Reserve, a protected area important for grassland conservation in South Africa. Pitfall traps were used to sample ant assemblages at six control sites and six rehabilitated sites. In addition, environmental and vegetation surveys were conducted at each site. We found that the ant assemblages differed significantly between the control and rehabilitated sites, although there was considerable overlap; the control sites supported a greater species density and higher abundance of ants than the rehabilitated sites. In total, 36 ant species were collected (control sites: 34 species; rehabilitated sites: 26 species). The environmental survey revealed that percentages of bare ground and coarse sand, as well as soil $\mathrm{pH}$, differed significantly between the control and rehabilitated sites. The control and rehabilitated sites also supported significantly different plant assemblages. Three indicator ant species were identified for the control sites: Crematogaster rectinota, Crematogaster amita and Monomorium fastidium. No indicator species were identified for the rehabilitated sites. These results suggest that recovery from the previous agricultural use of the area is still incomplete and highlights the lack of research examining the success of rehabilitation in the grassland biome.

Conservation implications: The present study illustrates the need for further research on rehabilitation techniques utilised in the grassland biome. This is of value as the remainder of South African grasslands are considered critically endangered.

\section{Introduction}

\section{Rehabilitation and the need for bioindicators}

Increasing human impacts on the environment have resulted in widespread degradation of ecosystems (Hobbs \& Norton 1996). As a result, there is a global drive to rehabilitate terrestrial and freshwater environments (Lake 2001). Typically, rehabilitation projects monitor aspects such as vegetation structure, species diversity and richness as well as nutrient cycling (Ruiz-Jaén \& Aide 2005; Van Aarde \& Smit 1997). A number of rehabilitation studies make use of biological indicators. These indicators provide a means to monitor and assess the state of an ecosystem over time (Cairns, McCormick \& Niederlehner 1993; Morellet et al. 2007). However, in order to be practical, these bioindicators need to meet certain criteria. They need to be sensitive enough to provide an early warning in the event of a disturbance, they should have a wide spatial distribution and they must provide a continuous assessment for several disturbance factors (Noss 1990). Such indicators can aid us in understanding the rehabilitation of previously disturbed land and prove valuable for future management projects.

\section{Ants as bioindicators}

Invertebrates are potentially valuable indicators for monitoring the success of rehabilitation (Andersen \& Sparling 1997). In particular, ants (Hymenoptera: Formicidae) have received much attention as ecological bioindicators. They are widespread, abundant, have a manageable species richness and perform many keystone functions and thus have the potential to be used for the assessment of rehabilitation (Fagan et al. 2010; Van Hamburg et al. 2004). They are important ecosystem engineers that are responsible for turning soil, seed dispersal, forming mutualistic relationships and are among the top predators of other invertebrates (Hölldobler \& Wilson 1990; Lach, Parr \& Abott 2010). As they are colonial, their response to disturbance may be very different from other invertebrates that are more susceptible to disturbance events (Lach et al. 2010). The removal of individuals, resulting from mortality caused by disturbance, may not lead to the eradication of the colony from the habitat. Thus, the response of ants to disturbance differs from 
that of other terrestrial plants and animals that may become locally extinct after a disturbance event (Andersen 2000; Lach et al. 2010). In response to disturbance, such as agriculture or mining activities, ant communities may show changes in species composition and interspecific interactions, as well as loss of taxonomic diversity and variation in the provision of ecosystem services (Lach et al. 2010).

Ants have been used as bioindicators in several projects involving ecosystem management, land rehabilitation and monitoring the degree of land degradation, as well as investigating the conservation status of various zones of land (Majer 1983). They have been successfully used as bioindicators of mine site rehabilitation in northern Australia (Andersen, Hoffman \& Somes 2003) and on rehabilitated ash dams associated with coal-fired power stations around the Highveld of South Africa (Van Hamburg et al. 2004). They have also been used to indicate pesticide contamination in cotton-growing areas in Australia (Weir 1978). Ants thus provide an important indication of the biotic and abiotic state of an ecosystem and ultimately reveal the impacts that various environmental changes can have on an ecosystem (Hodkinson \& Jackons 2005).

\section{The importance of grasslands}

Grasslands are regions of global importance and provide a series of important ecosystem services. These include the purification of water, flood attenuation and nutrient cycling, as well as carbon sequestration and storage (South African National Biodiversity Institute [SANBI] 2013). The South African grassland biome covers nearly $30 \%$ of the country's land surface and is home to a large majority of the country's population and several endangered and endemic species (Neke \& Du Plessis 2004; SANBI 2013). Increasing urbanisation and development has resulted in a substantial amount of land degradation in the South African grassland biome, resulting in its classification as critically endangered (Neke \& Du Plessis 2004). Despite this, grasslands throughout the country have received little conservation protection (Neke \& Du Plessis 2004). Despite the necessity to rehabilitate grasslands following disturbances such as mining or agriculture, there appears to be limited knowledge on grassland rehabilitation (Zaloumis \& Bond 2010). As rehabilitation may take many years, there is a need to quantify the extent to which ecosystems (such as grasslands) have been rehabilitated (Legg \& Nagy 2006). Bioindicators such as ants can fulfil this purpose. However, to date surprisingly little research has been done in South Africa on ant diversity in grasslands and how ant communities resemble each other following a disturbance.

This study investigated the success of the rehabilitation measures applied in an old agricultural land area on Rietvlei Nature Reserve. We compared ant assemblages in areas where rehabilitation measures were applied and in nearby untransformed, natural grassland areas as an indication of the effectiveness of rehabilitation. We also aimed to identify whether any indicator species were present in the rehabilitating and untransformed (control) sites of the reserve.

\section{Research method and design Study area}

The study took place on the southern region of Rietvlei Nature Reserve (between 25 $50^{\prime} \mathrm{S}, 28^{\circ} 15^{\prime} \mathrm{E}$ and $25^{\circ} 56^{\prime} \mathrm{S}$, $\left.28^{\circ} 19^{\prime} \mathrm{E}\right)$, a protected area important for grassland conservation in South Africa. The reserve covers an area of approximately 3870 ha. It is situated in close proximity to urban centres. The climate of the area is characterised by warm, wet summers that are followed by cold, dry winters, when frost is prevalent. Summer temperatures may reach highs of $34{ }^{\circ} \mathrm{C}$, which are contrasted by the low winter temperatures that can fall to $-2{ }^{\circ} \mathrm{C}$ (Marais 2004). The area has a mean annual rainfall of approximately $724 \mathrm{~mm}$ (1970-1999; Marais 2004). The plant composition of the reserve is typical of the grassland biome; the vegetation type of the area is described as Rand Highveld Grassland (Mucina \& Rutherford 2006).

Around 23 years ago, the reserve extended its southern boundary and incorporated land that was previously used for agriculture. Rehabilitation measures were employed on the land in an attempt to improve species diversity and ecological function. The rehabilitated areas were ploughed and sown with a mix of indigenous grass seeds (R. Marais 2014, pers. comm., Rietvlei Nature Reserve, Pretoria).

\section{Procedure}

\section{Ant sampling}

Sampling was carried out at 12 sites, 6 located in the rehabilitated area and 6 in untransformed (control) areas of the reserve. All sites were at a minimum distance of $200 \mathrm{~m}$ from old land boundaries to avoid edge effects and $300 \mathrm{~m}$ from other sampling sites to ensure independent sampling. At each site, 10 plastic pitfall traps $(55 \mathrm{~mm}$ in diameter and $70 \mathrm{~mm}$ deep) were arranged in two rows of five, positioned $10 \mathrm{~m}$ apart. The study was designed in such a manner so as to avoid or minimise the possibility of pseudoreplication that may have been introduced by having a single larger array with many traps and treating each array (rather than each trap) as a replicate. The traps were placed in the soil with the rim flush with the soil surface and partially filled with a mixture of water and propylene glycol. This non-toxic solution ensures the successful preservation of the captured specimens. A rain cover $(20-\mathrm{cm}$ plastic lid with four wire legs) was placed above each trap to avoid flooding. The traps were left in place for 3 days from 08 to 11 April 2014. The ant specimens found in each trap were removed and identified to species level where possible and their abundances recorded. Ants were identified to genus using Bolton (1994) and then to species where possible, using the most recent available keys to the genera concerned: for Agraulomyrmex, Prins (1983); Anoplolepis, Prins (1982); Crematogaster, Arnold (1920); Lepisiota, Arnold (1920); Leptogenys, Bolton (1975); Meranoplus, Bolton (1981); Monomorium, Bolton (1987); Technomyrmex, 
Bolton (2007) and Tetramorium, Bolton (1980). For some genera, such as Camponotus, Carebara, Dorylus, Pheidole, Plagiolepis and Solenopsis, no keys are presently available for the Afrotropical fauna; for these genera, as well as for species in other genera that could not be identified using the available keys, specimens were identified by comparison with reference material in the AfriBugs collection (AFRC). Where no formal name could be assigned, a morphospecies code matched to voucher material in the AFRC collection was applied. These codes are globally unique and images of most are available on AntWeb (http:/ / www.antweb.org) to allow cross-referencing between studies. All identifications were performed by S.L. Jamison under the guidance of P.G. Hawkes. A specimen of each of the species identified was mounted and labelled to produce a reference collection, which is housed at the Department of Zoology \& Entomology, University of Pretoria.

\section{Environmental factors}

Estimates of the percentage bare ground, rock, grass, shrub cover and height of the tallest plant were recorded in five $1-\mathrm{m}^{2}$ quadrats at each site. These quadrats were randomly selected from the immediate area around each of the sites. The quadrats were placed within a $10-\mathrm{m}$ perimeter around the pitfall traps in order to establish the best estimate of environmental factors within each of the respective sites. The Braun-Blanquet cover-abundance scale was used to quantify the cover of all plant species in three $1-\mathrm{m}^{2}$ quadrats at each site. A disk pasture meter was used to obtain measures of above-ground vegetation biomass. A total of 20 disk pasture meter height measurements were recorded at random at each site. We refer to these height measurements as a biomass index from here onwards.

A soil auger was used to collect a soil sample from the first $20 \mathrm{~cm}$ of soil at each of the sites. Soil was randomly sampled within a $10-\mathrm{m}$ perimeter around the pitfall traps. Three soil samples were randomly taken from each of the 12 sites. The three soil samples collected at each site were then combined and used as one sample to get an indication of the average soil conditions at each site. The percentage coarse sand, sand, silt and clay content of the soil as well as the soil $\mathrm{pH}$ and soil organic matter were determined using standard methods (Appendix 1). All soil analyses were conducted at the University of Pretoria in the Soil Sciences Department.

\section{Analysis}

Species diversity indices for the ant data were generated using PRIMER 5.2.0 software package (Clarke \& Warwick 2001). The indices included the Pielou (Pielou 1969) and Shannon-Weiner diversity indices (Shannon 2001). These diversity indices were compared between the rehabilitated and control sites with Welch two-sample $t$-tests (Welch 1947). Furthermore, Welch two-sample $t$-tests were used to test for significant differences between the number of ant species and the number of individuals found between rehabilitated and control sites.
Species richness in the two sites was compared using rarefaction curves with 95\% confidence intervals derived from unconditional variance estimates (Colwell et al. 2012). Richness estimators were generated using Estimate-S (v 9.1.0; Colwell 2013). We used three non-parametric species richness estimators and one parametric estimator in our analysis to correct for sampling bias. The non-parametric estimators were the incidence-based coverage estimator (ICE), the Chao 2 abundance-based richness estimator (Chao 2) and the Second-order Jackknife richness estimator (Jack 2). We used the Michaelis-Menton mean (MMMean) as the parametric estimator. We chose this suite of estimators as estimator performance varies depending on a range of factors, and no single estimator is universally accepted as superior to others (Smith \& Jones 2005). Sampling was considered adequate if the sample-based rarefaction curves and the curves of the species richness estimators converged closely at the highest observed values (Cardoso 2009; Cardoso et al. 2009; Longino, Coddington \& Colwell 2002; Magurran 2004). Observed richness as a percentage of estimated richness was used as a measure of inventory completeness (Jiménez-Valverde et al. 2010). The mean sampling completeness was calculated for the control and rehabilitated sites by averaging the completeness calculated for each of the different species richness estimators. Species richness was compared between the rehabilitated and control sites by plotting rarefaction curves with their 95\% confidence intervals. If the intervals overlapped, the differences between the treatments were taken to be not significant (Colwell et al. 2012).

An analysis of similarity (ANOSIM) and non-metric multidimensional scaling (nMDS) were performed to compare the ant assemblages in the rehabilitated and control areas. The similarity matrix was calculated using a BrayCurtis similarity measure and a fourth-root transformation in PRIMER 5.2.0 (Clarke \& Warwick 2001). The fourth-root transformation reduces the contribution of very abundant species (French \& Major 2001). ANOSIM generates a Global $R$ statistic that provides an indication of average dissimilarity between the assemblages being compared. Values closer to 1 indicate distinct differences, while values closer to 0 indicate high levels of similarity in species composition. To assess the contribution of different species to the differences between the rehabilitated and control sites, the similarity percentages for species contributions were applied to the data (SIMPER, PRIMER 5.2.0). A fourth-root transformation was again used to reduce the influence of dominant species.

Characteristic ant species (indicator species) were identified for each of the sites with the use of the Indicator Values Method (Dufrêne \& Legendre 1997) in the package labdsv (Roberts 2014), run in R 3.1.1 (R Development Core Team 2011). An analysis of the relative indicator values (IndVal) was performed to determine the specificity (uniqueness to specific sites) and fidelity (rate of recurrence within each site) of each species for a particular site and treatment (e.g. rehabilitating or control). Species that were found to have a value greater than $70 \%$, that is, species that occur 
predominantly in a particular habitat and occur frequently in that habitat were considered as reliable indicator species for the different sampling units. Rank abundance curves were also generated and allowed comparison of species composition between control and rehabilitated sites.

The values for percentage of bare ground, rock, grass, shrub and height of tallest plant were compared between control and rehabilitated sites using Welch's two-sample $t$-tests, which were also used to compare the percentages of coarse sand, sand, silt and clay, as well as soil $\mathrm{pH}$ and soil organic matter.

ANOSIM and nMDS were performed to compare the plant assemblages in the rehabilitated and control sites. The similarity matrix was calculated using a Bray-Curtis similarity measure and a fourth-root transformation in PRIMER 5.2.0 (Clarke \& Warwick 2001). The Braun-Blanquet scale was rescaled to range from 1 to 7 for the purpose of the ANOSIM and nMDS (Table 1-A2).

\section{Results}

\section{Ants}

In total, 3206 individuals representing 36 species were collected during the study (Table 1-A3). The control sites had a significantly higher species density $(t=6.618, p<0.001)$ and abundance $(t=4.674, p<0.001)$ than the rehabilitated sites (Figure 1). Additionally, the control sites had a significantly higher Pielou evenness index $(t=3.125, p<0.05)$ and Shannon-Weiner index $(t=6.789, p<0.001)$ than the rehabilitated sites (Figure 1). In total, 34 ant species were collected from the control sites, whereas only 26 species were collected from the rehabilitated sites. Of the 36 species collected in this study, 24 species $(66.7 \%)$ were present in both the control and rehabilitated sites. In total, 10 species $(27.8 \%)$ were unique to the control sites, whereas only 2 species $(5.6 \%)$ were unique to the rehabilitated sites (Table 1-A3).

The estimated species richness $\left(\mathrm{S}_{\text {est }}\right)$ for the ant samples collected from the control and rehabilitated sites did not converge closely with the richness estimators (Figure 1-A1). The mean sampling completeness for the rehabilitated sites was found to be $65.70 \%$, whereas the average sampling completeness for the control sites was $70.31 \%$ (from Table 1-A4 to Table 5-A4). However, as it is unlikely that we will ever reach an asymptotic endpoint, particularly for ants and other invertebrates (Gotelli et al. 2014), this level of sampling completeness is likely sufficient to draw conclusions about grassland rehabilitation. The confidence intervals on the rarefaction curves for the rehabilitated and control sites overlapped, indicating that there were no significant differences in species richness (Figure 2).

ANOSIM indicated that ant assemblages differed significantly between the treatments (Global $R=0.507, p=0.002$ ). The nMDS plot revealed that there was some separation between the control and rehabilitated sites, although some overlap is still evident (Figure 3). The replicates representing the control sites $(C)$ are clustered together at the top of the plot indicating smaller assemblage differences between these replicates than for the rehabilitated sites. The replicates representing four of the rehabilitated sites $(1 R, 3 R, 5 R$ and $6 R)$ are clustered together in the lower right quadrant of the plot. They are clustered less tightly than the control sites at the top of the plot. This indicates fairly large assemblage differences between the replicates within the rehabilitated sites compared with those of the control sites. In particular, sites $1 R$ and $6 R$ are plotted in close proximity to the control sites indicating
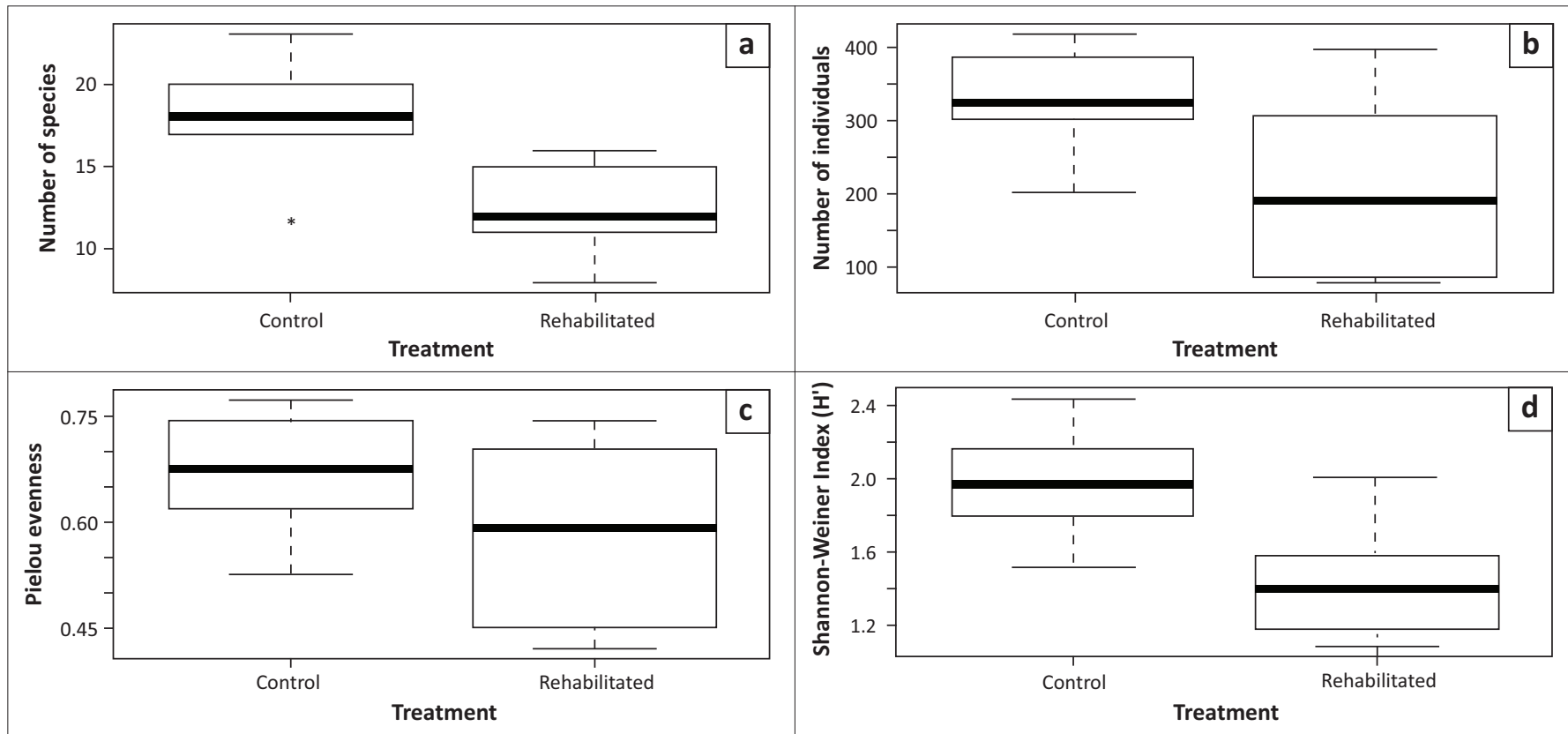

FIGURE 1: Box plots of ant diversity in the control and rehabilitated sites on Rietvlei Nature Reserve, showing (a) the number of species, (b) the number of individuals, (c) the Pielou evenness $\left(J^{\prime}\right)$ and $(d)$ the Shannon-Weiner Index $\left(H^{\prime}\right)$. 


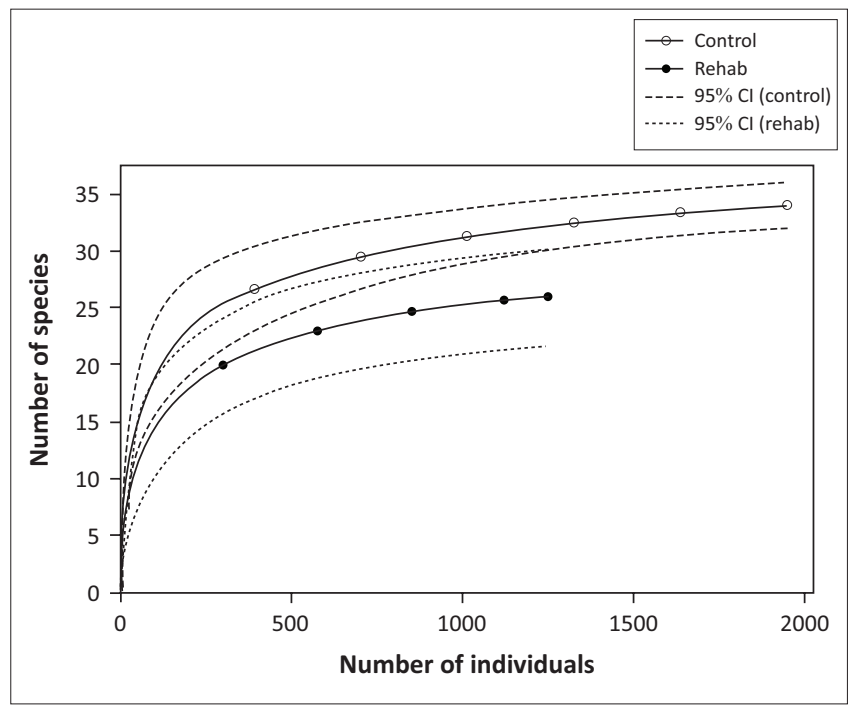

$\mathrm{Cl}$, confidence intervals.

FIGURE 2: Rarefaction curves with $95 \%$ confidence intervals comparing species richness in the control and rehabilitated (rehab) sites. Species richness should be compared for equal numbers of species in each treatment.

that the ant assemblages at these rehabilitated sites are similar to those of the control sites. Sites $2 \mathrm{R}$ and $4 \mathrm{R}$ are isolated from the clusters on either side of the plot indicating that the ant assemblages found at these sites are different from those found at the other sites of both treatment types. It is interesting that $2 \mathrm{C}$ is located near the rehabilitated sites within the nMDS plot. The potential impact of humanmediated activities could have influenced the habitat at this site. However, we have no information regarding the use of the area before the establishment of the reserve and cannot give a fully informed explanation.

The assemblage differences are further supported by the rank abundance curves observed for the different treatments (Figure 4). These rank abundance curves show only species that were represented by more than five individuals. The three most abundant species found in the control sites were Monomorium albopilosum Emery (641 individuals), Meranoplus peringueyi Emery (209 individuals) and Tetramorium bothae Forel (193 individuals). In comparison, the three most abundant species found in the rehabilitated sites included M. albopilosum (411 individuals), Tetramorium setuliferum Emery (278 individuals) and Pheidole megacephala Fabricius (177 individuals). Although many of the highly abundant species were present in both the rehabilitated and control sites, the control sites had more unique species than the rehabilitated sites (control: 10 unique species, rehabilitated: 2 unique species; Table 1-A3). The criteria needed to identify indicator species (IndVal > 70\%) were fulfilled for three species present in the control sites (Table 1-A5). These species include Crematogaster rectinota Forel (IndVal $=0.932, p=$ 0.004), Crematogaster amita Forel (IndVal $=1, p=0.003$ ) and Monomorium fastidium Bolton (IndVal $=0.808, p=0.031$ ). No indicator species were identified for the rehabilitated sites. The results from the rank abundance curves are further supported by the SIMPER results, which found C. amita to have the greatest contribution to the separation of the control and rehabilitated sites $(6.31 \%$ of total abundance; 51

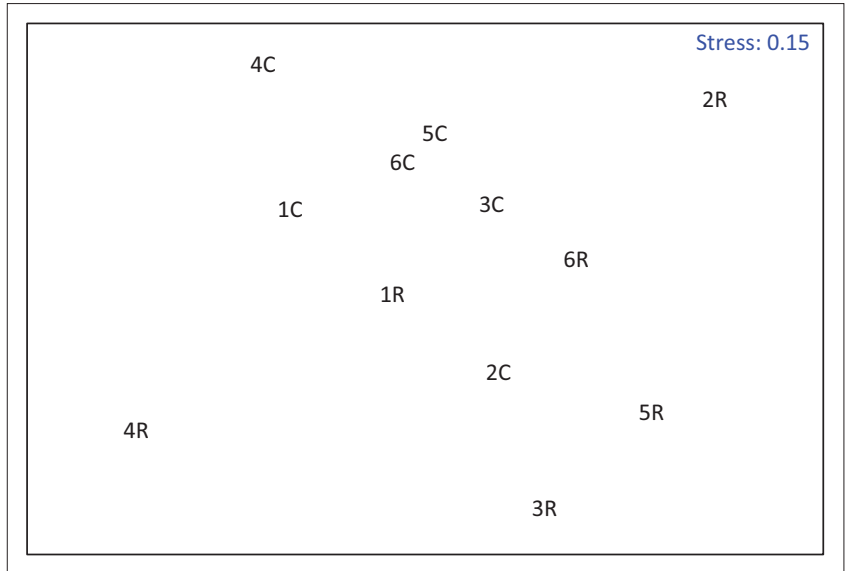

C, control; R, rehabilitated.

FIGURE 3: Non-metric multidimensional scaling plot indicating the similarity of ant assemblages among replicates of control and rehabilitated sites.

individuals in total for the control sites), followed by M. peringueyi (5.67\%; 209 individuals in control sites) and lastly M. fastidium (5.53\%; 167 individuals across control and rehabilitated sites). Although M. albopilosum had a total of 1052 individuals for both the control and rehabilitated sites, the overall contribution of this species to the separation of sites was only $4.27 \%$. The contribution of the other species was greater because of the difference in average abundance of the species between the sites. The mean abundance of M. albopilosum was 106.83 in the control sites and 68.50 in the rehabilitated sites.

\section{Environmental variables}

The mean percentage of bare ground was significantly higher in the rehabilitated than the control sites $(t=-3.193$, $p=0.003$; Figure 1-A2). There were no significant differences in the percentage cover of grass, rock, height of tallest plant and biomass index between the rehabilitated and control sites. The $\mathrm{pH}$ of the soil $(t=-2.754, p=0.021)$ and the percentage coarse sand $(t=2.275, p=0.0495)$ differed significantly between the rehabilitated and control sites (Figure 1-A3). However, the $t$-tests revealed that there was no significant difference in soil organic matter and percentage of sand, silt and clay content between the rehabilitated and control sites.

\section{Vegetation assemblages}

ANOSIM indicated that the plant assemblages differed significantly between the treatments (Global $R=0.712, p=$ $0.001)$. The Global $R$ statistic indicates fairly large assemblage differences between the control and rehabilitated sites. The nMDS plot illustrates that there is a clear distinction between the control and rehabilitated sites (Figure 1-A4). There is a larger amount of variation in the plant communities between the various control sites than there is between the rehabilitated sites. It can be seen that the plant community of the control and rehabilitated sites is still very different, 23 years after rehabilitation. 


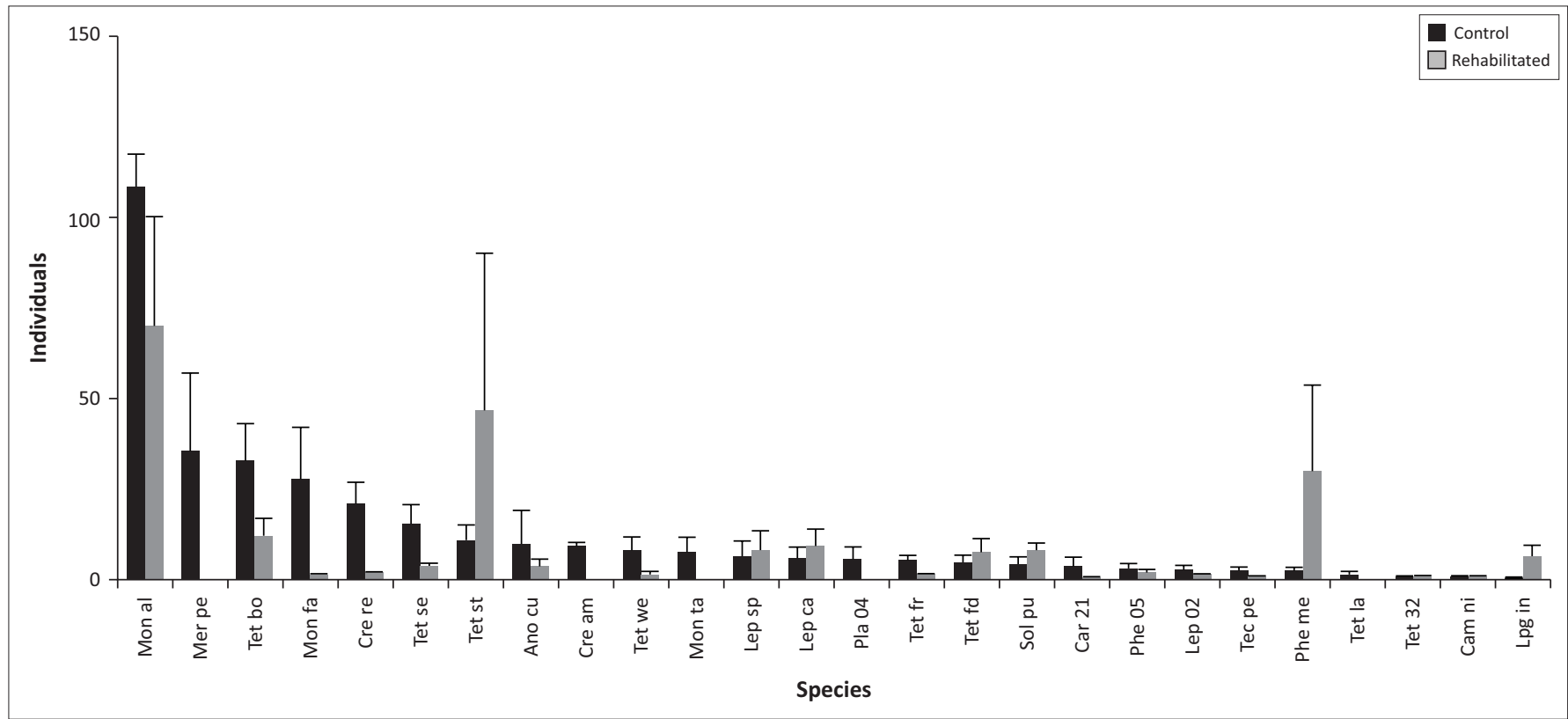

Species with fewer than five individuals per site were excluded from this analysis.

Values are presented as means with standard error bars.

The species abbreviations: Mon al, Monomorium albopilosum; Mer pe, Meranoplus peringueyi; Tet bo, Tetramorium bothae; Mon fa, Monomorium fastidium; Cre re, Crematogaster rectinota; Tet se, Tetramorium sericeiventre; Tet st, Tetramorium setuliferum; Ano cu, Anoplolepis custodiens Smith; Cre am, Crematogaster amita; Tet we, Tetramorium weitzeckeri; Mon ta, Monomorium taedium; Lep sp, Lepisiota spinosior; Lep ca, Lepisiota capensis; Pla 04, Plagiolepis afrc-za04; Tet fr, Tetramorium frenchi; Tet fd, Tetramorium frigidum; Sol pu, Solenopsis punctaticeps; Car 21, Carabara afrc-za21; Phe 05, Pheidole afrc-gau-05; Lep 02, Lepisiota afrc-za02; Tet la, Tetramorium laevithorax; Tet 32, Tetramorium afrc-za32; Cam ni, Camponotus niveosetosus; Lpg in, Leptogenys intermedia. FIGURE 4: Rank abundance plot for the rehabilitated and control grassland sites on Rietvlei Nature Reserve.

\section{Discussion}

This study found that the control sites on the Rietvlei Nature Reserve had significantly higher ant species density and abundance than the rehabilitated sites. In total, 34 ant species were collected from the control sites, whereas only 26 species were collected from the rehabilitated sites. Moreover, the control sites had a significantly higher Pielou evenness index and Shannon-Weiner diversity index than the rehabilitated sites. However, species richness was not significantly different between control and rehabilitated sites. There was a significant difference in the ant assemblages between the rehabilitated and control sites, although some convergence was evident.

\section{Influence of dominant ant species}

Of the 36 ant species collected in this study, $66.7 \%$ were present in both the control and rehabilitated sites (i.e. 24 species shared). However, a large portion of the difference between ant assemblages of the rehabilitated and control sites was because of the higher abundance of individuals present in the control sites (control: 1954 individuals, rehabilitated: 1252 individuals). The difference between ant assemblages may thus be because of a combination of the abundance of individuals and the composition of species present in the control and rehabilitated sites. In particular, two ant species (T. setuliferum and P. megacephala) had higher abundances in the rehabilitated sites than in the control sites, though neither species was identified as an indicator. Pheidole megacephala and several species of Tetramorium and Monomorium are said to be characteristic of disturbed areas (Andersen 2003; Samways, Caldwell \& Osborn 1996).
Furthermore, dominant ant species are known to affect the ant assemblages present in a region as well as influence species coexistence (Majer, Delabie \& Smith 1994; Samways et al. 1996). Samways et al. (1996) attributed the lower abundance of species recorded in the disturbed sites in their study to the presence of $P$. megacephala. Consequently, the high abundance of an aggressive species such as P. megacephala may explain the lower abundance of other ant species recorded in the rehabilitated sites in this study.

\section{Environmental variables}

Many of the environmental variables investigated in this study did not differ between the control and rehabilitated sites. The sites were similar in terms of total grass cover, other cover, rock cover, height of tallest plant and several soil properties (e.g. percentage sand, silt and clay content as well as soil organic matter). As a result, it could be said that the old agricultural land on the reserve has started to recover. Despite this, the percentage bare ground, soil $\mathrm{pH}$ and the percentage coarse sand differed significantly between the rehabilitated and control sites. This is important as such factors could influence the ant assemblages present in the sites. For instance, soil type is known to have an effect on the ant species present in a specific area (Andersen 1993; Koen \& Breytenbach 1988; Lindsey \& Skinner 2001). Unfortunately, the exact habitat requirements of ants are not well known (Lindsey \& Skinner 2001). However, the little research that has been done on this topic has revealed that ant assemblages are influenced by a number of habitat variables; soil moisture, soil type, the geology of an area, plant structural complexity and leaf litter cover (Andersen 1993; Koen \& Breytenbach 1988; Lindsey \& Skinner 2001). 
Many rehabilitation studies that have compared ant assemblages on rehabilitated and reference sites have established that the vegetation between the two compared treatments is very different. For example, van Hamburg et al. (2004) noted that the vegetation composition on rehabilitated ash dams and nearby natural grasslands was distinct. Consequently, these differences in plant composition result in different ant species assemblages as well as differences in ant species diversity (Van Hamburg et al. 2004). Also, a study by Zaloumis and Bond (2010) found differences between rehabilitated and control sites in a South African grassland; rehabilitated sites supported a much smaller community of resprouting forb species than the control sites. This is important as forb species make up much of the diversity of South African grasslands. The poor ability of forb species to reestablish after disturbance is attributed to their poor dispersal ability and lack of propagating sources (Dickson \& Busby 2008; Kardol et al. 2008; Zaloumis \& Bond 2010).

Several environmental factors such as soil properties can alter the direction of succession as well as the plant species present (Zaloumis \& Bond 2010). Also, the addition of nutrients such as nitrogen from fertilisers can influence the spread and species richness of weeds and alien plants, which has negative consequences for the native flora of the region (Zaloumis \& Bond 2010). Thus, a thorough understanding of the region's environmental variables and their impact on plant species is of importance, as ants are dependent on vegetation structure (Andersen 1995). The failure of successful rehabilitation of the plant community in grasslands could consequentially affect the ant assemblages present within the area. This is important as the present study found a significant difference between the plant assemblages of the control and rehabilitated sites on Rietvlei Nature Reserve. This difference in plant assemblages could possibly explain the difference in ant assemblages on the reserve because of factors such as substrate and vegetation have direct effects on the colonisation ability of different ant species (Van Hamburg et al. 2004). As a result, the differences in plant assemblages and specific environmental factors may explain the variation between ant assemblages of control and rehabilitated sites. Similarly, as ants are considered ecosystem engineers and often cause changes to soil, they too could be a contributing factor affecting the plant species composition within the area. As a result, ants could be driving much of the rehabilitation in the reserve old lands; however, more research is required before a conclusive decision can be made.

\section{Indicator species}

Three indicator species were identified, all of which were characteristic of the control sites. The indicator species were C. rectinota, C. amita and $M$. fastidium. No indicator species were identified for the rehabilitated sites.

Specialist ant predators are said to be highly sensitive to disturbance and thus are rarely recorded in disturbed habitats (Andersen et al. 2003; Hoffmann \& Andersen 2003). Included in the list of specialist predators (Andersen 2000) is the genus Leptogenys, in the tribe Ponerini. Only one species of this genus, Leptogenys intermedia Emery, was recorded during this study. However, the fact that this species was recorded in both the rehabilitated and control sites suggests that the rehabilitated sites have started acquiring the vegetation structure, compostition and arthropod fauna that is necessary to support the specialised diet of these predators (Andersen 2000). This is noteworthy as many authors have found specialist predators to be among the last species to colonise rehabilitating areas (Majer \& Beeston 1996; Hoffman \& Andersen 2003). This is interesting as not much is known regarding the potential effects of these species on their environment and thus requires further research.

\section{Conclusion}

Our results show that the ant assemblages on rehabilitated areas of the reserve are significantly different from those of surrounding undisturbed areas, although some convergence is evident. These differences are likely to be explained by a combination of factors, including the presence of certain dominant ant species, differences in plant species composition and differences in environmental factors (including percentage bare ground, percentage coarse sand and soil $\mathrm{pH})$. A conclusive statement regarding the success of rehabilitation efforts on the reserve is not possible given the lack of background information on recovery rates and compositional changes, but our study shows that rehabilitation of grasslands would benefit from a greater understanding of ant diversity and the factors that are responsible for driving this diversity. Further studies are needed to investigate the functional roles of particular ant species, especially those that are considered to be good indicator species.

\section{Acknowledgements}

We are grateful to everyone who assisted with this project; Chantal Ferreira and Jonathan Fisher are thanked for their assistance with the ant identifications. Our gratitude is also extended to the Rietvlei Nature Reserve and its staff members, especially Riaan Marais, who made this study possible. Furthermore, Wesley Daniels, Chantal Ferreira, Michael Potgieter, André van Tonder, Cavin Shivambu and Paul Akkermans are gratefully acknowledged for their assistance in the field. Our thanks are extended to the Soil Sciences Department of the University of Pretoria who allowed us to use their facilities when conducting the soil analyses. We would also like to thank the anonymous reviewers whose comments helped to improve the manuscript. We are grateful for funding received from the National Research Foundation.

\section{Competing interests}

The authors declare that they have no financial or personal relationships which may have inappropriately influenced them in writing this article. 


\section{Authors' contributions}

S-L.J., M.R., I.E. and P.H. conceived and designed the study. S-L.J., M.R. and I.E. performed fieldwork. S-L.J. and P.H. performed ant identifications. S-L.J., I.E. and M.R. performed statistical analyses; P.H. contributed identification tools. S-L.J., M.R., I.E. and P.H. wrote and edited the manuscript.

\section{References}

Andersen, A., 1993, 'Ants as indicators of restoration success at a uranium mine in tropical Australia', Restoration Ecology 1(3), 156-167. http://dx.doi.org/10.1111/ tropical Australia', Restoration
j.1526-100X.1993.tb00022.x

Andersen, A., 1995, 'A classification of Australian ant communities based on functional groups which parallel plant life-forms in relation to stress and disturbance', Journal of Biogeography 22(1), 15-29. http://dx.doi.org/10.2307/2846070

Andersen, A., 2000, 'A global ecology of rainforest ants: Functional groups in relation to environmental stress and disturbance', in D. Agosti, J.D. Majer, L.E. Alonso \& T.R. Schultz (eds.), Ants: Standard methods for measuring and monitoring biodiversity, pp. 25-34, Smithsonian Institution Press, Washington, DC.

Andersen, A., 2003, 'Ant biodiversity in arid Australia: Productivity, species richness and community organisation', Records of the South Australian Museum Monograph Series 7, 79-92.

Andersen, A., Hoffmann, B. \& Somes, J., 2003, 'Ants as indicators of minesite restoration: Community recovery at one of eight rehabilitation sites in central Queensland', Ecological Management and Restoration 4(1), 12-19. http://dx.doi. org/10.1046/j.1442-8903.4.s.2.x

Andersen, A. \& Sparling, G., 1997, 'Ants as indicators of restoration success: Relationship with soil microbial biomass in the Australian seasonal tropics', Restoration Ecology 5(2), 109-114. http://dx.doi.org/10.1046/j.1526-100X.1997. 09713.x

Arnold, G., 1920, 'A monograph of the Formicidae of South Africa, Myrmicinae', Annuals of the South African Museum 14(5), 403-578.

Bolton, B., 1975, 'A revision of the ant genus Leptogenys Roger (Hymenoptera: Formicidae) in the Ethiopian region with a review of the Malagasy species', Bulletin of the British Museum (Natural History) Entomology 31(7), 235-305. http://dx.doi.org/10.5962/bhl.part.29487

Bolton, B., 1980, 'The ant tribe Tetramoriini (Hymenoptera: Formicidae). The genus Tetramorium Mayr in the Ethiopian zoogeographical region', Bulletin of the British Museum (Natural History) Entomology 40(3), 193-384.

Bolton, B., 1981, 'A revision of the ant genera Meranoplus F. Smith, Dicroaspis Emery and Calyptomyrmex Emery (Hymenoptera: Formicidae) in the Ethiopian zoogeographical region', Bulletin of the British Museum (Natural History) Entomology 42(2), 43-81.

Bolton, B., 1987, 'A review of the Solenopsis genus-group and revision of Afrotropical Monomorium Mayr (Hymenoptera: Formicidae)', Bulletin of the British Museum (Natural History) Entomology 54(3), 263-452.

Bolton, B., 1994, Identification guide to the ant genera of the world, Harvard University Press, Cambridge.

Bolton, B., 2007, 'Taxonomy of the dolichoderine ant genus Technomyrmex Mayr (Hymenoptera: Formicidae) based on the worker caste', Contributions of the (Hymenoptera: Formicidae) based on the worke
American Entomological Institute 35(1), 1-150.

Cairns, J.R.J., McCormick, P.V. \& Niederlehner, B.R., 1993, 'A proposed framework for developing indicators of ecosystem health', Hydrobiologia 263(1), 1-44. http:// dx.doi.org/10.1007/BF00006084

Cardoso, P., 2009, 'Standardization and optimization of arthropod inventories - the case of Iberian spiders', Biodiversity and Conservation 18(14), 3949-3962. http:// dx.doi.org/10.1007/s10531-009-9690-7

Cardoso, P., Crespo, L.C., Carvalho, R., Rufino, A.C. \& Henriques, S.S., 2009, 'Ad-hoc vs. standardized and optimized arthropod diversity sampling', Diversity 1(1), 36-51. http://dx.doi.org/10.3390/d1010036

Clarke, K.R. \& Warwick, R.M., 2001, Change in marine communities: An approach to statistical analysis and interpretation, 2nd edn., PRIMER-E, Plymouth.

Colwell, R.K., 2013, 'EstimateS: Statistical estimation of species richness and shared species from samples', version 9.1.0, viewed May 2014, from http://www.purl. oclc.org/estimates

Colwell, R.K., Chao, A., Gotelli. N.J., Lin, S.Y., Mao, C.X., Chazdon, R.L. et al., 2012, 'Models and estimators linking individual-based and sample-based rarefaction, extrapolation, and comparison of assemblages', Journal of Plant Ecology 5(1), 3-21. http://dx.doi.org/10.1093/jpe/rtr044

Dickson, T.L. \& Busby, W.H., 2008, 'Forb species establishment increases with decreased grass seeding density and with increased forb seeding density in a Northeast Kansas, U.S.A., experimental prairie restoration', Restoration Ecology 17(5), 597-605. http://dx.doi.org/10.1111/j.1526-100X.2008.00427.x

Dufrêne, M. \& Legendre, P., 1997, 'Species assemblages and indicator species: The need for a flexible asymmetrical approach', Ecological Monographs 67(3), 345366. http://dx.doi.org/10.2307/2963459

Fagan, K.C., Pywell, R.F., Bullock, J.M. \& Marrs, R.H., 2010, 'Are ants useful indicators of restoration success in temperate grasslands?', Restoration Ecology 18(3), 373379. http://dx.doi.org/10.1111/j.1526-100X.2008.00452.x
French, K. \& Major, R.E., 2001, 'Effect of an exotic Acacia (Fabaceae) on ant assemblages in South African fynbos', Austral Ecology 26(4), 303-310. http://dx. doi.org/10.1046/j.1442-9993.2001.01115.x

Gotelli, N.J., Ellison, J.A., Dunn, R.R. \& Sanders, N.J., 2014, 'Counting ants (Hymenoptera: Formicidae): Biodiversity sampling and statistical analysis for myrmecologists', Myrmecological News 15, 13-19.

Hobbs, R.J. \& Norton, D.A., 1996, 'Towards a conceptual framework for restoration ecology', Restoration Ecology4(2), 93-110. http://dx.doi.org/10.1111/j.1526-100X. 1996.tb00112.x

Hodkinson, I.D. \& Jackson, J.K., 2005 'Terrestrial and aquatic invertebrates as bioindicators of environmental monitoring with particular reference to mountain ecosystems', Environmental Management 35(5), 649-666. http://dx.doi. org/10.1007/s00267-004-0211-x

Hoffmann, B.D. \& Andersen, A.N., 2003, 'Responses of ants to disturbance in Australia, with particular reference to functional groups', Austral Ecology 28(4), 444-464. http://dx.doi.org/10.1046/j.1442-9993.2003.01301.x

Hölldobler, B. \& Wilson, E.O., 1990, The ants, Springer-Verlag, Cambridge.

Howard, S., 1998, 'Verbal protocol analysis', in B. Henderson-Sellers, A. Simons \& H. Younessi (eds.), The open process specification, pp. 272-274, Addison Wesley, Sydney.

Jiménez-Valverde, A., Baselga, A., Melic, A. \& Txasko, N., 2010, 'Climate and regional beta-diversity gradients in spiders: Dispersal capacity has nothing to say?', Insect Conservation and Diversity 3(1), 51-60. http://dx.doi.org/10.1111/j.1752-4598. 2009.00067.x

Kardol, P., Wal, A.V.D., Bezemer, T.M., Boer, W.D., Duyts, H., Holtkamp, R. et al., 2008, 'Restoration of species-rich grasslands on ex-arable land: Seed addition outweighs soil fertility reduction', Biological Conservation 141(9), 2208-2217. http://dx.doi. org/10.1016/j.biocon.2008.06.011

Koen, J.H. \& Breytenbach, W., 1988, 'Ant species richness of fynbos and forest ecosystems in the southern Cape', South African Journal of Zoology 23(3), 184188. http://dx.doi.org/10.1080/02541858.1988.11448100

Lach, L., Parr, C.L. \& Abott, K.L., 2010, Ant ecology, Oxford University Press, Oxford.

Lake, P.S., 2001, 'On the maturing of restoration: Linking ecological research and restoration', Ecological Management and Restoration 2(2), 110-115. http://dx. doi.org/10.1046/j.1442-8903.2001.00074.x

Legg, C.J. \& Nagy, L., 2006, 'Why most conservation monitoring is, but need not be, a waste of time', Journal of Environmental Management 78(2), 194-199. http:// dx.doi.org/10.1016/j.jenvman.2005.04.016

Lindsey, P.A. \& Skinner, J.D., 2001, 'Ant composition and activity patterns as determined by pitfall trapping and other methods in three habitats in the semiarid Karoo', Journal of Arid Environments 48(4), 551-568. http://dx.doi. org/10.1006/jare.2000.0764

Longino, J.T., Coddington, J. \& Colwell, R.K., 2002, 'The ant fauna of a tropical rain forest: Estimating species richness three different ways', Ecology 83(3), 689-702. forest: Estimating species richness three different ways', Ecology 83(3),
$\mathrm{http} / / / \mathrm{dx}$.doi.org/10.1890/0012-9658(2002)083[0689:TAFOAT]2.0.CO;2

Magurran, A.E., 2004, Measuring biological diversity, Blackwell, Oxford.

Majer, J.D., 1983, 'Ants: Bio-indicators of minesite rehabilitation, land-use, and land conservation', Environmental Management 7(4), 375-383. http://dx.doi. org/10.1007/BF01866920

Majer, J.D. \& Beeston, G., 1996, 'The biodiversity integrity index: An illustration using ants in Western Australia', Conservation Biology 10(1), 65-73. http://dx.doi org/10.1046/j.1523-1739.1996.10010065.x

Majer, J.D., Delabie, J.H.C. \& Smith, R.B., 1994, 'Arboreal ant community patterns in Brazilian cocoa farms', Biotropica 26(1), 73-83. http://dx.doi.org/10.2307/2389112

Marais, R., 2004, 'A plant ecological study of the Rietvlei Nature Reserve, Gauten Province', Magister Agriculturae thesis, Department of Animal, Wildlife and Grassland Sciences, University of the Free State.

Morellet, N., Gailllard, J.M., Hewison, A.J., Ballon, P., Boscardin, Y., Duncan, P. et al., 2007, 'Indicators of ecological change: New tools for managing populations of large herbivores', Journal of Applied Ecology 44(3), 634-643. http://dx.doi. org/10.1111/j.1365-2664.2007.01307.x

Mucina, L. \& Rutherford, M.C., 2006, The vegetation of South Africa, Lesotho and Swaziland, South African National Biodiversity Institute, Pretoria.

Neke, K.S. \& Du Plessis, M.A., 2004, 'The threat of transformation: Quantifying the vulnerability of grasslands in South Africa', Conservation Biology 18(2), 466-477.

Noss, R.F., 1990, 'Indicators for monitoring biodiversity: A hierarchical approach', Conservation Biology 4(4), 355-364. http://dx.doi.org/10.1111/j.1523-1739.1990. tb00309.x

Pielou, E.C., 1969, An introduction to mathematical ecology, Wiley, New York.

Prins, A.J., 1982, 'Review of Anoplolepis with reference to male genitalia, and notes on Acropyga (Hymenoptera, Formicidae)', Annuals of the South African Museum Acropyga (Hym
89(3), 215-247.

Prins, A.J., 1983, 'A new ant genus from southern Africa (Hymenoptera, Formicidae)', Annuals of the South African Museum 94(1), 1-11.

R Development Core Team, 2011, R: A language and environment for statistical computing, R Foundation for statistical Computing, Vienna, viewed June 2014 from http://www.R-project.org

Rawson-Tetley, R., Animal shelter manager, computer software, viewed 11 January 2005, from http://sheltermanager.sourceforge.net

Roberts, D.W., 2014, 'Labdsv: Ordination and multivariate analysis for ecology' R package version 1.6-1', viewed June 2014, from http://CRAN.R-project.org/ package $=$ labdsv 
Ruiz-Jaén, M.C. \& Aide, T.M., 2005, 'Vegetation structure, species diversity, and ecosystem processes as measures of restoration success', Forest Ecology and Management 218(1), 159-173.

Samways, M.J., Caldwell, P.M. \& Osborn, R., 1996, 'Ground-living invertebrate assemblages in native, planted and invasive vegetation in South Africa', Agriculture, Ecosystems and Environment 59(1), 19-32.

South African National Biodiversity Institute (SANBI), 2013, Grasslands Ecosystem Guidelines: Landscape interpretation for planners and managers, Compiled by Cadman, M., de Villiers, C., Lechmere-Oertel, R. \& McCulloch, D. South African National Biodiversity Institute, Pretoria.

Shannon, C.E., 2001, 'A mathematical theory of communication', ACM SIGMOBILE Mobile Computing and Communications Review 5(1), 3-55. http://dx.doi. org/10.1145/584091.584093

Smith, K.L. \& Jones, M.L., 2005, 'Watershed-level sampling effort requirements for determining riverine fish species composition', Canadian Journal of Fisheries and Aquatic Sciences 62(7), 1580-1588. http://dx.doi.org/10.1139/f05-098
Van Aarde, R. \& Smit, A., 1997, The ecology of rehabilitating coastal dunes at Richards Bay, University of Pretoria, Pretoria.

Van Hamburg, H., Andersen, A.N., Meyer, W.J. \& Robertson, H.G., 2004, 'Ant community development on rehabilitated ash dams in the South African Highveld', Restoration Ecology 12(4), 552-558, http://dx.doi.org/10.1111/j.1061-2971. 2004.00421.x

Weir, J.S., 1978, The ant Iridomyrmex as a biological indicator of pesticide contamination, Report for N.S.W. State Pollution Control Commission, New South Wales, Australia.

Welch, B.L., 1947, 'The generalization of "student's" problem when several different population variances are involved', Biometrika 34(1/2), 28-35. http://dx.doi.org/ $10.2307 / 2332510$

Zaloumis, N.P. \& Bond, W.J., 2010, 'Grassland restoration after afforestation: No direction home?', Austral Ecology 36(4), 357-366. http://dx.doi.org/10.1111/j. 1442-9993.2010.02158.x 


\section{Appendix 1: Methods and materials used for soil analyses}

Soil samples were taken from each of the sites with the aid of a soil auger. The auger was twisted into the soil until the chamber filled with soil. The soil was placed into labelled plastic bags. Three soil samples were taken randomly from the area around each site. The three samples taken at each site were combined and used as one sample. The soil pH, soil organic matter, sand, silt and clay contents were determined for the 12 sites surveyed.

The $\mathrm{pH}$ of the soil was determined with the use of a $\mathrm{pH}$ meter (accurate to $0.05 \mathrm{pH}$ units). Initially, twelve $50-\mathrm{cm}^{3}$ beakers were labelled and weighted on a balance (accurate to $0.1 \mathrm{~g}$ ) and their weights recorded. A $10-\mathrm{g}$ sample of each of the 12 soil samples was placed into the respectively labelled beakers. An automatic dispenser was used to dispense $25 \mathrm{~cm}^{3}$ of de-ionised water into each of the beakers. The beakers were shaken for approximately 5 $\mathrm{s}$ and allowed to stand for $60 \mathrm{~min}$. Each beaker was then shaken before the electrodes of the $\mathrm{pH}$ meter were placed into the soil sample. The results obtained are reported as $\mathrm{pH}\left(\mathrm{H}_{2} \mathrm{O}\right)$.

The sand, silt and clay contents of the soil were determined with the use of the particle size distribution method. Twelve beakers ( $250 \mathrm{~cm}^{3}$ capacity) were weighed and their weights recorded. Each beaker received $50 \mathrm{~g}$ of soil from a respective site. To each beaker of soil, $10 \mathrm{~cm}^{3}$ of Calgon dispersing solution (a mixture that contains sodium hexametaphosphate $\left[\mathrm{NaPO}_{4}\right]$ and sodium carbonate $\left[\mathrm{Na}_{2} \mathrm{CO}_{3}\right]$ and de-ionised water) was added. The contents of a beaker were placed into a dispersion cup and filled to approximately $150 \mathrm{~cm}^{3}$ with de-ionised water. The sample was then mixed for $5 \mathrm{~min}$ with the use of an electric mixer (10 $000 \mathrm{rpm}-13000 \mathrm{rpm})$. The sand fraction of the soil was removed by washing the dispersed sample on a $0.053-\mathrm{mm}$-size sieve. This sieve would ensure that only silt and clay could pass through the funnel into a $1-\mathrm{dm}^{3}$ cylinder. The washing process was continued until the percolate was clear. The sieve was then removed from the cylinder, and the sand was transferred into a labelled beaker. This process was repeated for all 12 soil samples. The beakers containing the separated sand were dried in a drying oven at $105^{\circ} \mathrm{C}$ to constant mass. The samples were then weighed and the masses of the sand (excluding the weight of the beaker) were recorded. The mass of the sand fraction was given as A. Following this, the cylinders containing the silt and clay were filled to the $1-\mathrm{dm}^{3}$ mark. Each of the cylinders was stirred with a hand stirrer for a period of $30 \mathrm{~s}$. A 'blank' was prepared by adding $10 \mathrm{~cm}^{3}$ Calgon to a $1-\mathrm{dm}^{3}$ cylinder of water. The cylinders were left undisturbed for a total period of 6 hours $30 \pm 5 \mathrm{~min}$. Once this time had elapsed, a standard hydrometer (with Bouyoucos scale in grams per litre, ranging from -5 to 60 ) was slowly inserted into the suspension of each cylinder and the recording (C) was taken. The hydrometer was placed into each suspension carefully in order not to mix the solution. At this time, a temperature reading was taken.

The particle sizes were calculated as follows:

$A=$ Mass of sand fraction $(\mathrm{g})$

$B=$ Hydrometer reading of blank
$C=$ Hydrometer reading of sample

$\mathrm{M}=$ Mass $(\mathrm{g})$ of soil used

Sand fraction:

Percentage sand $=A * 100 / M$

[Eqn 1]

Clay fraction:

To calculate the clay reading, the blank hydrometer reading was subtracted from the sample reading $(C-B)$ and the percentage clay under the appropriate temperature was determined using a particle size distribution table (where $\mathrm{E}$ is the reading obtained from the table).

Percentage clay $=\mathrm{E} * 50 / \mathrm{M}$

[Eqn 2]

Silt fraction:

Percentage silt $=100-\%$ clay $-\%$ sand

[Eqn 3]

The soil organic matter was determined by weighing 12 labelled beakers $\left(50 \mathrm{~cm}^{3}\right)$ and recording the masses of each. An approximate mass of between $10 \mathrm{~g}$ and $20 \mathrm{~g}$ of each soil sample was weighed and placed into the relevant beakers. The beakers were placed in a drying oven at $105^{\circ} \mathrm{C}$ and left overnight to ensure that any moisture in the samples was removed. When removed from the drying oven, the samples were weighed and transferred to a furnace $\left(550^{\circ} \mathrm{C}\right)$ and left for a period of 16 hours. The beakers were then weighed and the mass of the soil organic matter determined. This percentage was then subtracted from the previously determined sand fraction to produce a new adjusted sand fraction.
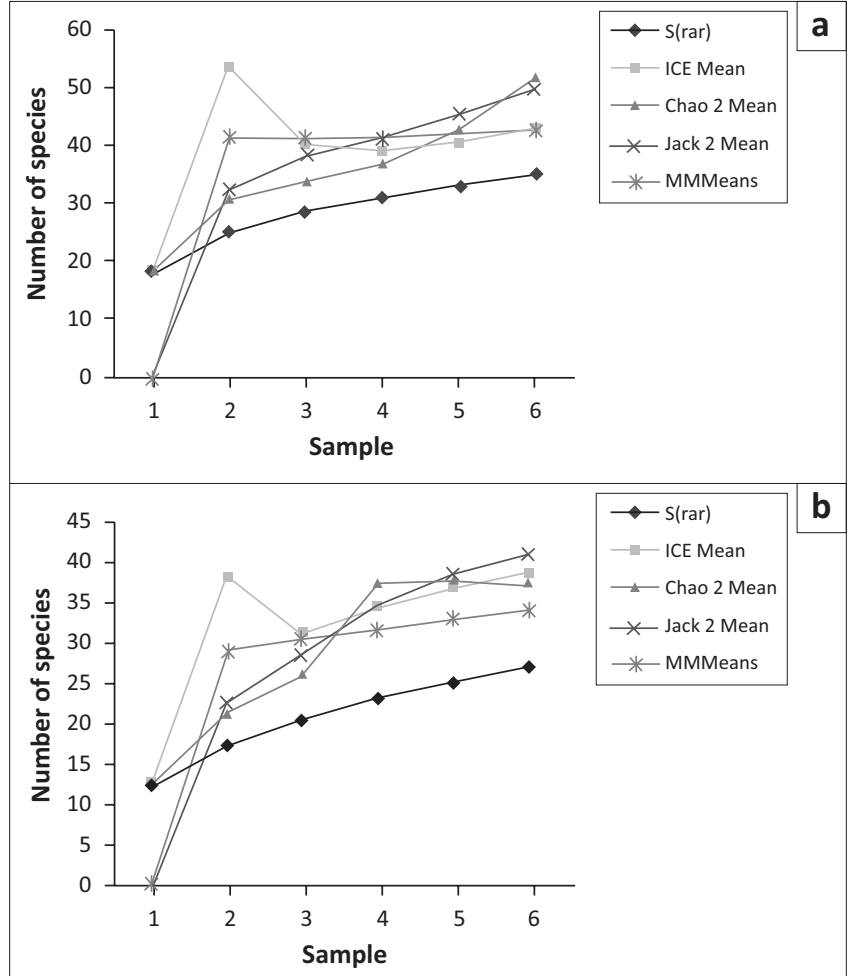

In total, 10 traps were used to collect the ant species at each of the 12 sites. The traps were set for a period of 72 hours.

FIGURE 1-A1: Sample-based rarefaction curves indicating the number of species (Srar), ICE mean (incidence-based coverage estimator), Chao 2 mean (abundancebased richness estimator), Jack 2 mean (Second-order Jackknife richness estimator) and the Michaelis-Menton mean (MMMeans) richness estimators of ants in (a) control sites and (b) rehabilitated sites of the Rietvlei Nature Reserve. 


\section{Appendix 2: Braun-Blanquet scale for vegetation cover}

TABLE 1-A2: Plant morphospecies abundance quantified with the use of the Braun-Blanquet abundance scale and the altered scale that was used during the analysis of data.

\begin{tabular}{lcc}
\hline Cover or abundance & Braun-Blanquet scale & Altered scale for analysis \\
\hline Very rare species & $r$ & 1 \\
Less than $1 \%$ cover & + & 2 \\
$1 \%-5 \%$ cover & 1 & 3 \\
$5 \%-25 \%$ cover & 2 & 4 \\
$25 \%-50 \%$ cover & 3 & 5 \\
$50 \%-75 \%$ cover & 4 & 7 \\
$75 \%-100 \%$ cover & 5 & 7 \\
\hline
\end{tabular}
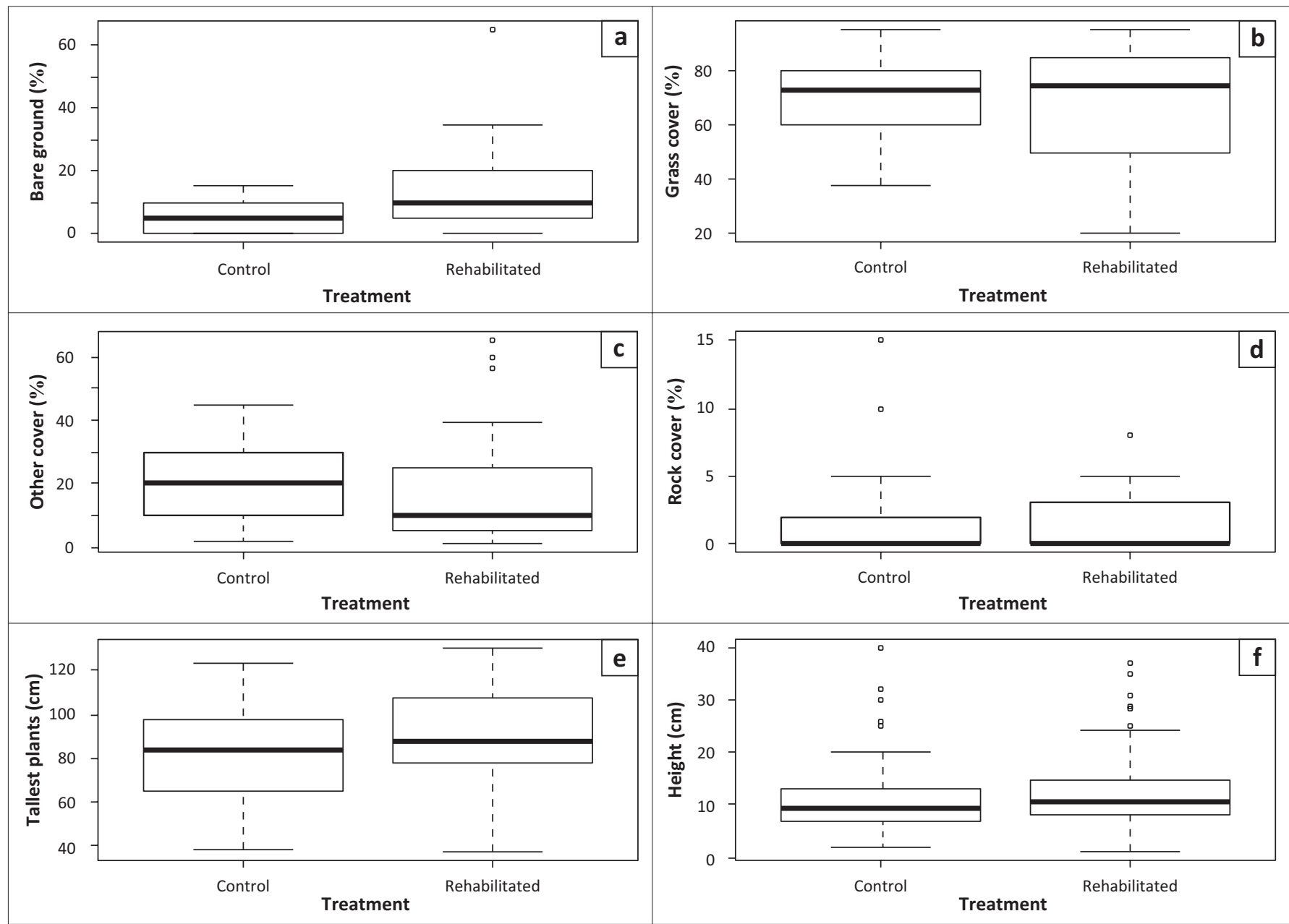

FIGURE 1-A2: Box plots indicating the various vegetation indices recorded in $1 \mathrm{~m} \times 1 \mathrm{~m}$ quadrats, (a) percentage bare ground, (b) percentage grass cover, (c) percentage of other cover (forbs, shrubs and herbs), (d) percentage rock cover, (e) height (cm) of the tallest plant in each of the quadrats for each of the sites and ( $f$ ) height of the biomass recorded from the disk pasture meter. 


\section{Appendix 3: Ant species lists for various data sets}

Specimens were identified to species level where possible. Specimens that could not be identified to species level were identified to genus and assigned to numbered morphospecies.

TABLE 1-A3: The number of individuals per species, listed per subfamily, which were collected in total for rehabilitated and control sites on the Rietvlei Nature Reserve, South Africa.

\begin{tabular}{|c|c|c|c|}
\hline Species & Control sites & Rehabilitated sites & Total \\
\hline Agraulomyrmex afrc-za01 & 3 & 1 & 4 \\
\hline Anoplolepis custodiens (Smith, 1858) & 57 & 20 & 77 \\
\hline Camponotus afrc-za12 & 0 & 3 & 3 \\
\hline Camponotus niveosetosus (Mayr, 1862) & 2 & 4 & 6 \\
\hline Carebara afrc-za21 & 16 & 1 & 17 \\
\hline Carebara afrc-za01 & 4 & 0 & 4 \\
\hline Crematogaster amita (Forel, 1913) & 51 & 0 & 51 \\
\hline Crematogaster rectinota (Forel, 1913) & 123 & 9 & 132 \\
\hline Dorylus helvolus (Linnaeus, 1764) & 1 & 0 & 1 \\
\hline Formicine genus afrc-g-za01 sp. afrc-za04 & 2 & 0 & 2 \\
\hline Lepisiota afrc-za02 & 13 & 5 & 18 \\
\hline Lepisiota capensis (Mayr, 1862) & 33 & 52 & 85 \\
\hline Lepisiota crinita (Mayr, 1895) & 1 & 1 & 1 \\
\hline Lepisiota imperfecta (Santschi, 1926) & 4 & 0 & 4 \\
\hline Lepisiota spinosior (Forel, 1913) & 35 & 46 & 81 \\
\hline Leptogenys intermedia (Emery, 1902) & 1 & 35 & 36 \\
\hline Meranoplus peringueyi (Emery, 1886) & 209 & 0 & 209 \\
\hline Monomorium albopilosum (Emery, 1895) & 641 & 411 & 1052 \\
\hline Monomorium fastidium (Bolton, 1987) & 162 & 5 & 167 \\
\hline Monomorium taedium (Bolton, 1987) & 41 & 0 & 41 \\
\hline Monomorium torvicte (Bolton, 1987) & 2 & 0 & 2 \\
\hline Pheidole afrc-gau-05 & 14 & 7 & 21 \\
\hline Pheidole megacephala (Fabricius, 1793) & 12 & 179 & 191 \\
\hline Pheidole sp. 04 cf megacephala major & 0 & 3 & 3 \\
\hline Pheidole tenuinodis (Mayr, 1901) & 2 & 1 & 3 \\
\hline Plagiolepis afrc-za04 & 33 & 0 & 33 \\
\hline Solenopsis punctaticeps (Mayr, 1865) & 21 & 44 & 65 \\
\hline Technomyrmex pallipes (Smith, 1876) & 13 & 4 & 17 \\
\hline Tetramorium afrc-za32 & 3 & 3 & 6 \\
\hline Tetramorium bothae (Forel, 1910) & 193 & 69 & 262 \\
\hline Tetramorium frenchi (Forel, 1914) & 28 & 7 & 35 \\
\hline Tetramorium frigidum (Arnold, 1926) & 27 & 42 & 69 \\
\hline Tetramorium laevithorax (Emery, 1895) & 6 & 0 & 6 \\
\hline Tetramorium sericeiventre (Emery, 1877) & 90 & 18 & 108 \\
\hline Tetramorium setuliferum (Emery, 1895) & 62 & 278 & 340 \\
\hline Tetramorium weitzeckeri (Emery, 1895) & 45 & 6 & 51 \\
\hline
\end{tabular}




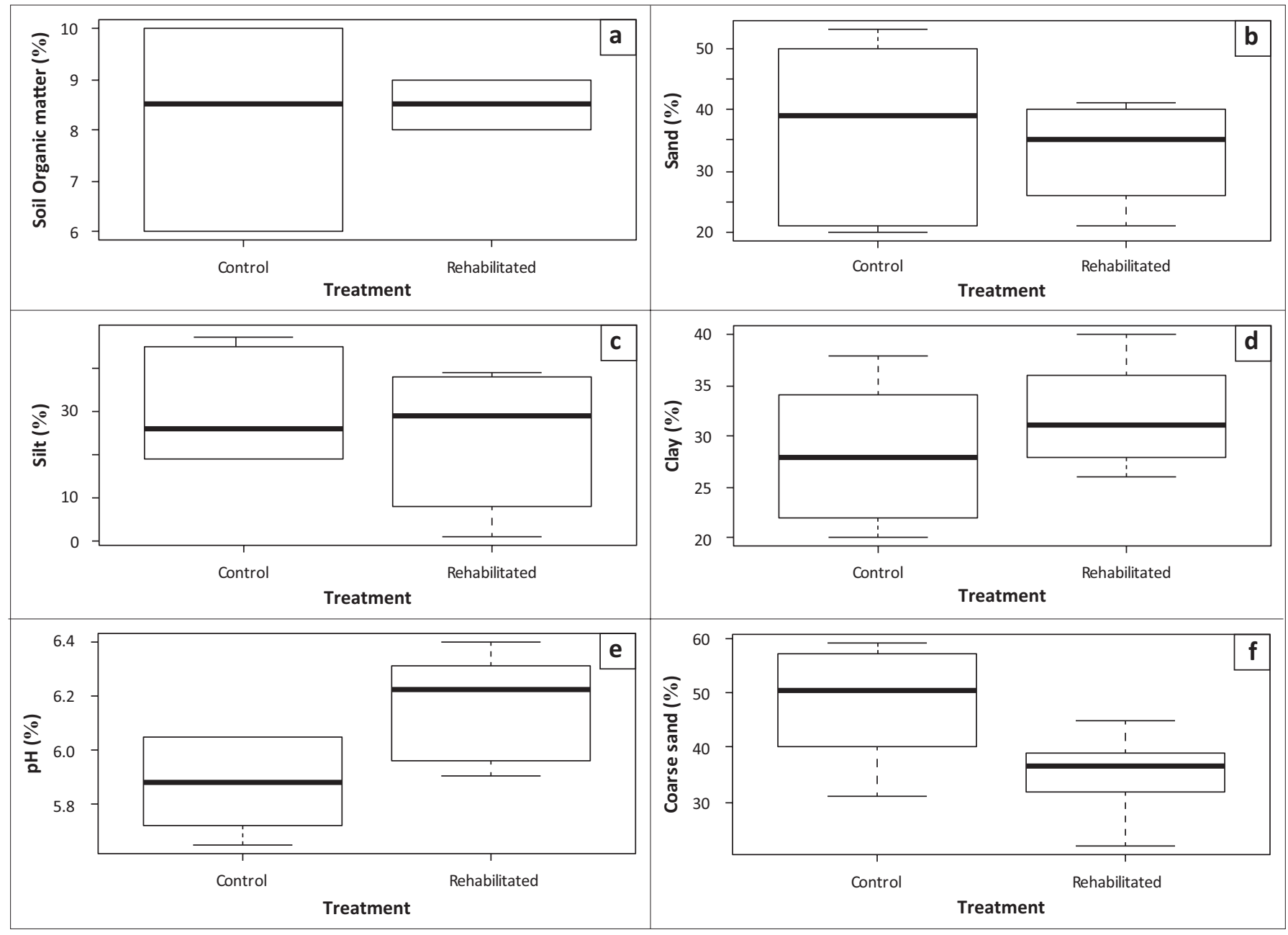

FIGURE 1-A3: Box plots indicating the properties of the soil collected from the different treatments: (a) percentage soil organic matter, (b) percentage sand, (c) percentage silt, (d) percentage clay, (e) $\mathrm{pH}$ and (f) percentage coarse sand. 


\section{Appendix 4: Tables illustrating sampling completeness calculated for the rehabilitated and control sites}

\begin{tabular}{llccc}
\multicolumn{1}{l}{ TABLE 1-A4: Richness estimator values as obtained from Estimate-S (v 9.1.0; Colwell 2013). } \\
\hline Site & S(est) & ICE mean & Chao 2 mean & Jack 2 mean \\
\hline 1 & 17.83 & 18.54 & 18.54 & 0.00 \\
2 & 24.93 & 53.30 & 30.39 & 32.28 \\
3 & 28.65 & 40.32 & 33.53 & 38.46 \\
4 & 31.13 & 39.19 & 36.91 & 41.43 \\
5 & 33.17 & 40.53 & 42.62 & 45.34 \\
6 & 35.00 & 42.89 & 51.81 & 41.33 \\
\hline
\end{tabular}

Values are calculated for the six control sites. The estimated species richness is given as $\mathrm{S}_{\text {est. }}$.

ICE, incidence-based coverage estimator.

TABLE 2-A4: Richness estimator values as obtained from Estimate-S (v 9.1.0; Colwell 2013).

\begin{tabular}{|c|c|c|c|c|c|}
\hline Site & $S(e s t)$ & ICE mean & Chao 2 mean & Jack 2 mean & MMMeans (1 run) \\
\hline 1 & 12.33 & 12.57 & 12.57 & 0.00 & 0.00 \\
\hline 2 & 17.33 & 38.31 & 21.37 & 22.54 & 29.15 \\
\hline 3 & 20.45 & 31.16 & 25.82 & 28.49 & 30.23 \\
\hline 4 & 23.00 & 34.22 & 37.27 & 34.52 & 31.60 \\
\hline 5 & 25.17 & 36.73 & 37.72 & 38.49 & 32.93 \\
\hline 6 & 27.00 & 38.55 & 37.08 & 40.83 & 34.12 \\
\hline
\end{tabular}

Values are calculated for the six rehabilitated sites. The estimated species richness is given as $\mathrm{S}_{\text {est }}$

ICE, incidence-based coverage estimator.

TABLE 3-A4: The reliability of each inventory was calculated for the control sites.

\begin{tabular}{|c|c|c|c|c|c|}
\hline Site & S(est) & (S(est)/ICE mean)*100 & (S(est)/Chao 2 mean)*100 & (S(est)/Jack 2 mean) $* 100$ & (S(est)/MMMeans)*100 \\
\hline 1 & 17.83 & 96.17 & 96.17 & 0.00 & 0.00 \\
\hline 2 & 24.93 & 46.77 & 82.03 & 77.23 & 60.17 \\
\hline 3 & 28.65 & 71.06 & 85.45 & 74.49 & 69.57 \\
\hline 4 & 31.13 & 79.43 & 84.34 & 75.23 & 75.32 \\
\hline 5 & 33.17 & 81.84 & 77.83 & 73.16 & 79.39 \\
\hline 6 & 35.00 & 81.60 & 67.55 & 70.14 & 82.49 \\
\hline Mean & 28.45 & 76.15 & 82.23 & 61.71 & 61.16 \\
\hline
\end{tabular}

Given as: completeness $=$ [observed species richness/estimated species richness $] \times 100$.

ICE, incidence-based coverage estimator.

TABLE 4-A4: The reliability of each inventory was calculated for the rehabilitated sites.

\begin{tabular}{|c|c|c|c|c|c|}
\hline Site & $S($ est) & (S(est)/ICE mean)*100 & (S(est)/Chao 2 mean)*100 & (S(est)/Jack 2 mean)*100 & (S(est)/MMMeans)*100 \\
\hline 1 & 12.33 & 98.09 & 98.09 & 0.00 & 0.00 \\
\hline 2 & 17.33 & 45.24 & 81.09 & 76.89 & 59.45 \\
\hline 3 & 20.45 & 65.63 & 79.20 & 71.78 & 67.65 \\
\hline 4 & 23.00 & 67.21 & 61.71 & 66.63 & 72.78 \\
\hline 5 & 25.17 & 68.53 & 66.73 & 65.39 & 76.43 \\
\hline 6 & 27.00 & 70.04 & 72.82 & 66.13 & 79.13 \\
\hline Mean & 20.88 & 69.12 & 76.61 & 57.80 & 59.24 \\
\hline
\end{tabular}

Given as: completeness $=$ [observed species richness/estimated species richness] $\times 100$.

ICE, incidence-based coverage estimator.

TABLE 5-A4: Overall sampling completeness.

\begin{tabular}{lcc}
\hline Richness estimator & Control sites & Rehabilitated sites \\
\hline ICE mean & 76.15 & 69.12 \\
Chao 2 mean & 82.23 & 76.61 \\
Jack 2 mean & 61.71 & 57.80 \\
MMMeans (1 run) & 61.16 & 59.24 \\
\hline Average (\%) & $\mathbf{7 0 . 3 1}$ & $\mathbf{6 5 . 7 0}$ \\
\hline
\end{tabular}

These values are calculated by averaging the richness estimates across each of the sites.

ICE, incidence-based coverage estimator. 


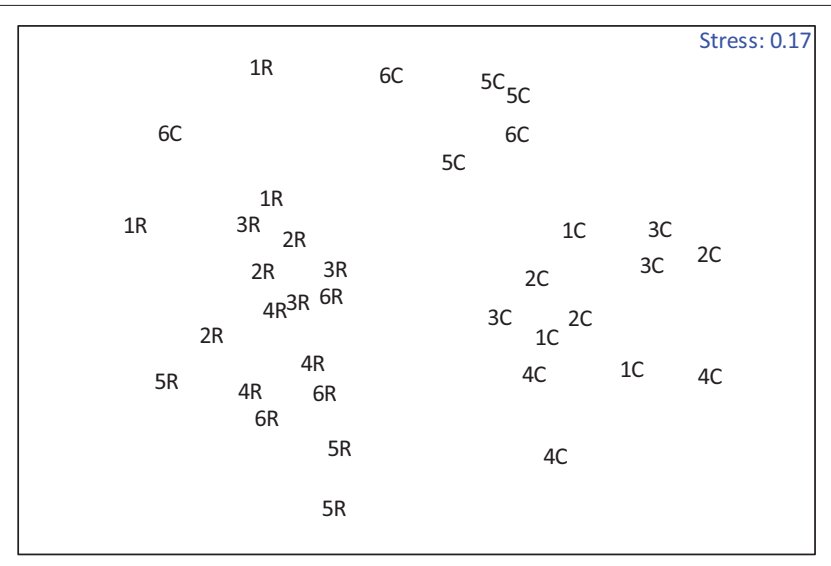

$C$, control; R, rehabilitated

FIGURE 1-A4: Non-metric multidimensional scaling plot indicating the similarity of plant assemblages among replicates of control and rehabilitated sites. 


\section{Appendix 5: List of Indicator values}

TABLE 1-A5: Indicator values generated in Rstudio. Species fulfilling the criteria (IndVal $>70 \%, p<0.05$ ) are identified as indicator species.

\begin{tabular}{|c|c|c|c|}
\hline Species & Control sites & Rehabilitated sites & $p$-value \\
\hline Agraulomyrmex afrc-za01 & 0.125 & 0.042 & 1.000 \\
\hline Anoplolepis custodiens (Smith, 1858) & 0.247 & 0.087 & 0.889 \\
\hline Camponotus afrc-za12 maculatus.cf & 0.000 & 0.167 & 1.000 \\
\hline Camponotus niveosetosus (Mayr, 1862) & 0.056 & 0.222 & 1.000 \\
\hline Carebara afrc-za21 & 0.476 & 0.008 & 0.305 \\
\hline Carebara afrc-za01 & 0.333 & 0.000 & 0.443 \\
\hline Crematogaster amita (Forel, 1913) & 0.932 & 0.045 & 0.004 \\
\hline Crematogaster rectinota (Forel, 1913) & 1.000 & 0.000 & 0.003 \\
\hline Dorylus helvolus (Linnaeus, 1764) & 0.167 & 0.000 & 1.000 \\
\hline Formicine genus afrc-g-za01 sp. afrc-za04 & 0.167 & 0.000 & 1.000 \\
\hline Lepisiota afrc-za02 & 0.361 & 0.046 & 0.387 \\
\hline Lepisiota capensis (Mayr, 1862) & 0.259 & 0.612 & 0.377 \\
\hline Lepisiota crinita (Mayr, 1895) & 0.083 & 0.083 & 1.000 \\
\hline Lepisiota imperfecta (Santschi, 1926) & 0.167 & 0.000 & 1.000 \\
\hline Leptogenys intermedia (Emery, 1902) & 0.005 & 0.486 & 0.328 \\
\hline Meranoplus peringueyi (Emery, 1886) & 0.667 & 0.000 & 0.071 \\
\hline Monomorium albopilosum (Emery, 1895) & 0.609 & 0.326 & 0.244 \\
\hline Monomorium fastidium (Bolton, 1987) & 0.808 & 0.010 & 0.031 \\
\hline Monomorium taedium (Bolton, 1987) & 0.500 & 0.000 & 0.168 \\
\hline Monomorium torvicte (Bolton, 1987) & 0.167 & 0.000 & 1.000 \\
\hline Pheidole afrc-gau-05 & 0.222 & 0.056 & 0.712 \\
\hline Pheidole megacephala (Fabricius, 1793) & 0.042 & 0.780 & 0.191 \\
\hline Pheidole sp. 04 cf megacephala major & 0.000 & 0.167 & 1.000 \\
\hline Pheidole tenuinodis (Mayr, 1901) & 0.111 & 0.056 & 1.000 \\
\hline Plagiolepis afrc-za04 & 0.667 & 0.000 & 0.066 \\
\hline Solenopsis punctaticeps (Mayr, 1865) & 0.215 & 0.677 & 0.193 \\
\hline Technomyrmex pallipes (Smith, 1876) & 0.510 & 0.078 & 0.235 \\
\hline Tetramorium afrc-za32 & 0.250 & 0.083 & 0.553 \\
\hline Tetramorium bothae (Forel, 1910) & 0.614 & 0.219 & 0.263 \\
\hline Tetramorium frigidum (Arnold, 1926) & 0.326 & 0.406 & 0.868 \\
\hline Tetramorium laevithorax (Emery, 1895) & 0.167 & 0.000 & 1.000 \\
\hline Tetramorium sericeiventre (Emery, 1877) & 0.694 & 0.139 & 0.172 \\
\hline Tetramorium setuliferum (Emery, 1895) & 0.122 & 0.409 & 0.871 \\
\hline Tetramorium weitzeckeri (Emery, 1895) & 0.588 & 0.020 & 0.173 \\
\hline
\end{tabular}

Three species were found to fulfil the criteria. All indicators were characteristic of control sites. 